\title{
Flexibilidade Cognitiva no Ensino de Ciências: Uma Revisão Bibliográfica ${ }^{+*}$
}

Muryel Pyetro Vidmar ${ }^{1}$

Universidade Federal de Santa Maria (UFSM)

Santa Maria - RS

Inés Prieto Schmidt Sauerwein ${ }^{1}$

Universidade Federal de Santa Maria (UFSM)

Santa Maria - RS

\section{Resumo}

Apresentamos neste artigo os resultados de uma revisão bibliográfica que teve como objetivos principais: (i) situar a flexibilidade cognitiva nas áreas de ensino e pesquisa em ensino de Ciências, e (ii) buscar subsidios para consubstanciar o desenvolvimento da flexibilidade cognitiva através da elaboração e avaliação de atividades didáticas de Física. Consideramos, neste contexto, a importância da recontextualização dos conhecimentos científicos. Explicitada por diversos autores e pelos documentos oficiais voltados ao ensino médio de Física, é ela que possibilita aos estudantes lidar com as situações que vivenciam ou venham a vivenciar, muitas delas novas e inéditas. Encontramos na Teoria da Flexibilidade Cognitiva (TFC) a base teórico-metodológica para essas questões. Isso porque ela enfatiza o desenvolvimento da flexibilidade cognitiva como essencial na construção, organização e reestruturação do conhecimento face a novas situações e contextos de utilização. Nessa linha, a revisão bibliográfica foi realizada em trinta e três periódicos da área, e abrangeu as publicações contidas no período de 1990 a 2017, em consonância com a proposição da TFC. Buscamos analisar aqueles trabalhos que possuíam ênfase na flexibilidade cognitiva, a partir de critérios elaborados de acordo com os referidos objetivos. Como um dos resultados dessa revisão bibliográfica, constatamos que a flexibilidade cognitiva ainda é

\footnotetext{
${ }^{+}$Cognitive Flexibility in Science Education: A Bibliographic Review

* Recebido: setembro de 2019. Aceito: agosto de 2020.

${ }^{1}$ E-mails: muryel.vidmar@ufsm.br; ines.p.sauerwein@ufsm.br
} 
pouco trabalhada no âmbito do ensino de Ciências, o que explicita a relevância e necessidade de ampliação das investigações sobre a temática. Outro resultado importante consistiu na inexistência de artigos de revisão de literatura sobre flexibilidade cognitiva na área, de modo que essa revisão se mostrou pertinente nesse âmbito. Como principal resultado obtido, destacamos a diversidade de metodologias de ensino, instrumentos de avaliação e focos de avaliação nas propostas analisadas. Entendemos que isso pode contribuir para a estruturação de atividades didáticas que visam a um processo de ensino-aprendizagem de Física mais flexível, bem como para uma análise coerente $e$ abrangente dos aspectos envolvidos no desenvolvimento da flexibilidade cognitiva. Flexibilidade essa que é essencial para uma formação mais ampla e articulada, que visa à aplicação do conhecimento em novos contextos.

Palavras-chave: Revisão Bibliográfica; Flexibilidade Cognitiva; Ensino de Ciências.

\begin{abstract}
In this paper we present the results of a bibliographical review whose main objectives were: (i) to situate cognitive flexibility in the areas of teaching and research in Science education, and (ii) to seek subsidies to materialize the development of cognitive flexibility through the elaboration and evaluation of didactic activities of Physics. We consider, in this context, the importance to recontextualize scientific knowledge. Explained by several authors and by the official documents aimed at the high school of Physics, it makes possible students deal with the situations they experience or may experience, many of them new and original. We find in the Cognitive Flexibility Theory (CFT) the theoreticalmethodological basis for this issues. That's because it emphasizes the development of cognitive flexibility as essential in the construction, organization and restructuring of knowledge in the face of new situations and contexts of use. In this context, the bibliographic review was done in thirty-three journals of the area, and covered the publications in the period from 1990 to 2017, in consonance with the proposal of CFT. We aim to analyze papers that emphasized cognitive flexibility, based on criteria elaborated according to the specified objectives. As one of the results of this bibliographic review, we found that cognitive flexibility is still little handled in the scope of Science education, which explains the
\end{abstract}


relevance and necessity of expanding the research about the tematic. Another important result was the inexistence of literature review articles on cognitive flexibility in this area, so that this review was relevant in this scope. As a main result, we highlight the diversity of teaching methodologies, evaluation tools and evaluation focuses in the proposals analyzed. We understand that this can contribute to the structuring of didactic activities that aim at a more flexible teaching-learning process of Physics, as well as for a coherent and comprehensive analysis of the aspects involved in the development of cognitive flexibility. This flexibility is essential for a broader and more articulated formation, which aims apply knowledge in new contexts.

Keywords: Bibliographic Review; Cognitive Flexibility; Science Education.

\section{Introdução}

Políticas públicas educacionais voltadas ao ensino médio de Física - como os PCN+ (BRASIL, 2002), as Orientações Curriculares para o Ensino Médio (BRASIL, 2006) e as Diretrizes Curriculares Nacionais da Educação Básica (BRASIL, 2013) - explicitam a ideia de que a formação geral que a escola precisa proporcionar aos seus estudantes tem como objetivo principal ampliar a compreensão que eles têm do mundo em que vivem.

Este objetivo mais amplo requer, sobretudo, que os estudantes se apropriem de conhecimentos científicos e desenvolvam competências para lidar com as situações que vivenciam ou que venham a vivenciar, muitas delas novas e inéditas (BRASIL, 2002, 2013).

Em situações complexas e/ou inéditas, é preciso que o estudante seja capaz de aplicar os conhecimentos construídos (PESSOA; NOGUEIRA, 2009) para compreendê-las. A noção de competências pretende que o estudante "mobilize seus conhecimentos em contextos distintos daquele em que aprendeu, para poder se relacionar com o mundo" (BRASIL, 2006, p. 48).

Nesta linha, Pozo e Crespo (2009) abordam a velocidade de mudança dos conhecimentos e das demandas formativas na sociedade atual, enfatizando a importância de que os sujeitos sejam aprendizes flexíveis que possam dispor de procedimentos e capacidades de aprendizagem que os possibilite adaptarem-se às referidas demandas. Os autores enfatizam que a meta da educação precisa ser “[...] tornar mais transferível e generalizável o conhecimento. A aprendizagem escolar deve ser situada em sua origem, em seu ponto de partida, mas suas metas devem ser mais gerais, devem facilitar a transferência do conhecimento de um contexto para outro" (POZO; CRESPO, 2009, p. 129, grifo dos autores).

A Teoria da Flexibilidade Cognitiva, proposta no final da década de 80 por Rand Spiro e colaboradores, vai ao encontro das referidas preocupações. Ela enfatiza o 
desenvolvimento da flexibilidade cognitiva como essencial na construção, organização e aplicação do conhecimento face a novas situações e contextos de utilização (SPIRO; JEHNG, 1990). Os pressupostos dessa teoria foram desenvolvidos a partir da constatação de que os estudantes tinham dificuldade em aplicar os conhecimentos em novas situações (SOUSA, 2004; ALEIXO, 2008).

Em relação ao ensino de Ciências, Pozo e Crespo (2009) apontam que é muito comum que algo aprendido pelos estudantes se dilua ou se torne difuso quando se trata de aplicar esse conhecimento a um problema ou situação nova. Os autores também citam o caso específico dos problemas quantitativos, nos quais se observa fraca generalização dos procedimentos construídos para outros contextos. Isso porque, assim que é alterado o formato ou o conteúdo conceitual do problema, os estudantes apresentam dificuldades em aplicar o que foi aprendido a essa nova situação (POZO; CRESPO, 2009).

Em consonância, Echeverría e Pozo (1998, p. 41) destacam que a aplicação dos conhecimentos construídos para um novo contexto “[...] constitui o problema de aprendizagem mais difícil de superar, tanto para as teorias da aprendizagem como para a própria prática didática e educacional". Os autores abordam que essa aplicação se torna difícil de um assunto para outro e de uma área para outra, mas especialmente quando se trata de um conhecimento construído em aula para um contexto mais cotidiano. E essa dificuldade ocorre principalmente devido à diferença entre os contextos nos quais o estudante aprende inicialmente e os novos contextos para os quais precisa fazer a aplicação (ECHEVERRÍA; POZO, 1998).

Neste contexto, considerando a dificuldade na aplicação dos conhecimentos científicos (POZO; CRESPO, 2009; ECHEVERRÍA; POZO, 1998), bem como a referida importância da flexibilidade cognitiva, buscamos, neste trabalho, apresentar os resultados de uma revisão bibliográfica realizada em publicações de periódicos das áreas de ensino e pesquisa em ensino de Ciências.

Essa pesquisa teve como objetivos principais situar a flexibilidade cognitiva nas referidas áreas; e, a partir disso, buscar subsídios para consubstanciar o desenvolvimento da flexibilidade cognitiva através da elaboração e avaliação de atividades didáticas de Física.

\section{Referencial teórico}

\section{II.1 Flexibilidade cognitiva no âmbito da Teoria da Flexibilidade Cognitiva}

Quando diante de situações complexas e/ou novas situações, é necessário que o sujeito seja capaz de aplicar conhecimentos e desenvolver novo repertório comportamental para compreendê-las. É nesse contexto que surge a importância da flexibilidade cognitiva.

O conceito de flexibilidade cognitiva é estudado por vários autores, que atribuem a ele diversas interpretações e significados (GUERRA, 2012). Optamos nesse trabalho pela perspectiva contida no âmbito da Teoria da Flexibilidade Cognitiva, visto que ela: aborda o 
conceito de flexibilidade cognitiva com ênfase nos processos de ensino-aprendizagem; discute aspectos necessários para o desenvolvimento da flexibilidade cognitiva; e apresenta estratégias para consubstanciar esses aspectos e, com isso, contribuir para o desenvolvimento da flexibilidade cognitiva.

A Teoria da Flexibilidade Cognitiva (TFC) consiste em uma teoria de ensinoaprendizagem, representação do conhecimento e aplicação do conhecimento (SPIRO; JEHNG, 1990; SPIRO et al., 1992; PEDRO, 2005; LEITE; LEÃO, 2015), desenvolvida por Rand Spiro e colaboradores no final da década de 1980 (CARVALHO, 1998).

O objetivo principal da TFC é promover o desenvolvimento da flexibilidade cognitiva (DIAS, 2000; PINHO, 2006; CARVALHO, 2011), que consiste na "capacidade que o sujeito desenvolve de, perante uma situação nova, reestruturar o conhecimento para a solucionar" (CARVALHO; PINTO; MONTEIRO, 2002, p. 1).

Não se pretende, deste modo, a mera memorização de um assunto. Pretende-se, isso sim, que o sujeito, quando deparado com uma situação detentora de novidade, seja capaz de reestruturar as suas estruturas de conhecimento por forma a solucionar um dado problema, isto é, adquira a flexibilidade cognitiva necessária para a transferência de conhecimento (PEDRO; MOREIRA, 2000, p. 31).

Nesse contexto, a transferência de conhecimentos está relacionada com a aplicação do que foi aprendido a novas situações. E para isso, desenvolver a flexibilidade cognitiva é imprescindível (CARVALHO, 1998; CARVALHO; PINTO; MONTEIRO, 2002; RAMOS; SEGUNDO, 2018).

Uma situação nova de aplicação de conhecimento envolve a combinação de diversos conceitos (PEDRO, 2005), podendo estar associada, por exemplo, a um problema a ser resolvido (SPIRO; JEHNG, 1990; CARVALHO, 2000). O aspecto central na identificação dessa situação nova é que nela precisa haver características que a diferem da situação de aprendizagem (CARVALHO, 1998).

A base para o desenvolvimento da flexibilidade cognitiva consiste na capacidade de reorganização do conhecimento necessário para resolver uma situação nova (PINHO, 2006). E para se obter essa reestruturação, é preciso que o conhecimento seja construído de uma forma particular (CARVALHO, 1998, 2000).

A TFC se estrutura a partir do referido objetivo principal e, nesse sentido, visa a proporcionar ao sujeito a construção de esquemas flexíveis ao longo do processo de construção do conhecimento (DESCHRYVER; SPIRO, 2009; OLIVEIRA; SILVA; AQUINO, 2017). Uma das mais importantes recomendações para essa construção flexível é a utilização de múltiplas representações do conhecimento (SPIRO; JEHNG, 1990), que favoreçam a aplicação desse para novas situações (REZENDE; COLA, 2004; REZENDE; GARCIA; COLA, 2006).

As múltiplas representações do conhecimento se referem a dois aspectos principais: i) múltiplas formas de organização do conhecimento, através de casos, mini casos e temas de 
análise conceitual interligados (SPIRO et al., 1992; REZENDE, 2001; SOUZA; LEÃO, 2015); e ii) múltiplas mídias - textos, imagens, gráficos, animações, vídeos - para apresentação do conhecimento (caso, mini caso e tema) (PEDRO, 2005).

De modo a contribuir para consubstanciar o desenvolvimento da flexibilidade cognitiva, a TFC apresenta algumas estratégias, as quais serão discutidas a seguir.

\section{II.2 Estratégias para o desenvolvimento da flexibilidade cognitiva}

A TFC apresenta estratégias de ensino para o desenvolvimento da flexibilidade cognitiva, estruturadas a partir dos seguintes elementos: caso, mini caso, tema de análise conceitual, comentário temático e travessia temática (SPIRO; JEHNG, 1990).

Buscando dar resposta ao desenvolvimento do domínio da complexidade e da capacidade de aplicar o conhecimento de maneira flexível para situações novas, a TFC utiliza uma abordagem centrada no estudo de casos (CARVALHO, 2000; CARVALHO; PINTO; MONTEIRO, 2002; PEDRO, 2005; MOREIRA; PEDRO; NOGUEIRA, 2011). Nesse sentido, o ponto de partida para analisar um domínio de conhecimento é um caso (PINHO, 2006).

De acordo com Spiro e Jehng (1990), casos são coisas que realmente acontecem. Podem ser um caso médico, um evento histórico, uma notícia, um exemplo, uma situação em contexto (PINHO, 2006; CARVALHO, 2011; VASCONCELOS; LEÃO, 2012). Consistem em situações concretas em que se aplica o conhecimento conceitual (CARVALHO, 2000). A utilização de casos no ensino busca proporcionar uma aprendizagem contextualizada (CARVALHO, 1998; SILVA; LEÃO; SOUZA, 2015).

Cabe ressaltar também a sobrecarga cognitiva que a utilização dos casos pode impor na construção de conhecimentos, pelo fato de se constituírem em unidades complexas (MOREIRA; PEDRO; NOGUEIRA, 2011). Tendo isso em vista, os autores da teoria enfatizam a necessidade de decompô-los em unidades menores, denominadas mini casos, de modo a explicitar os aspectos relevantes dos casos (SPIRO; JEHNG, 1990; PEDRO, 2005). Assim, o mini caso consiste na unidade fundamental de ensino (SPIRO; COLLINS; RAMCHANDRAN, 2007a), uma vez que a complexidade de um caso inviabiliza que ele desempenhe esse papel (PEDRO, 2005).

Os mini casos possibilitam abordar a complexidade a partir de pequenas unidades, de modo que aspectos que se dissipariam no todo passem a ter a sua importância (CARVALHO, 1998, 2000, 2011; REZENDE; COLA, 2004; MOREIRA; PEDRO; NOGUEIRA, 2011). Isso permite uma análise mais detalhada e uma melhor compreensão da situação (SOUSA, 2004).

Essa é abordagem prevista na TFC: iniciar o estudo por conhecer o todo, o assunto na íntegra, para, a partir daí, analisar as partes que o constituem (CARVALHO; PINTO; MONTEIRO, 2002). Assim, busca-se tornar a complexidade cognitivamente gerenciável para o estudante. Em vez de partir de um tratamento simples para o complexo, o processo de ensino-aprendizagem inicia com tratamentos complexos, porém situados em mini casos 
cognitivamente gerenciáveis, auxiliando também na subsequente reestruturação do conhecimento (SPIRO; JEHNG, 1990; PEDRO, 2005; SPIRO; COLLINS; RAMCHANDRAN, 2007a).

Ao fornecer possíveis formas de análise de um caso (MOREIRA; PEDRO; NOGUEIRA, 2011), os mini casos permitem que aspectos relevantes de casos analisados anteriormente possam auxiliar no estudo de novas situações de aplicação de conhecimento. Nesse sentido, os mini casos constituem-se em uma das dimensões de flexibilidade presentes na TFC (PEDRO, 2005).

Realizada a decomposição dos casos complexos em mini casos com menor grau de complexidade, a próxima etapa consiste na análise desses mini casos (SPIRO; JEHNG, 1990). Assim como os casos são analisados considerando seus aspectos relevantes - explicitados pelos mini casos -, cada mini caso também é analisado através dos diversos temas de análise conceitual que são relevantes para ele (SPIRO; JEHNG, 1990; CARVALHO; PINTO; MONTEIRO, 2002; REZENDE; COLA, 2004).

De acordo com os autores da TFC, temas de análise conceitual se referem a conceitos, princípios, leis e teorias, que variam de acordo com a área do saber (CARVALHO et al., 2002). Se constituem nos conhecimentos teóricos necessários para a compreensão dos mini casos e casos (CARVALHO, 2000; MOREIRA; PEDRO; NOGUEIRA, 2011). Nesse sentido, os temas precisam ser ensinados em contexto e não de forma abstrata, de modo que a construção do significado desses seja influenciada pelas características do contexto de sua utilização (PEDRO, 2005).

Os temas desempenham, dessa forma, um papel fundamental, operando nos mini casos uma desconstrução essencial para a concretização das múltiplas representações de conhecimento e de múltiplos esquemas interpretativos (PEDRO, 2005; SOUZA; LEÃO, 2015), que se constituem em dimensões de flexibilidade dessa teoria.

Realizada a seleção dos casos, mini casos e temas de análise conceitual, é preciso então efetuar a análise dos casos e mini casos através dos referidos temas. É nesse contexto que são produzidos o que os autores da TFC denominam comentários temáticos, que consistem em comentários que explicitam as diversas formas de aplicação de um determinado tema a uma dada situação (mini caso) (SPIRO; JEHNG, 1990; REZENDE; COLA, 2004; SOUSA, 2004; PEDRO, 2005; PINHO, 2006; MOREIRA; PEDRO; NOGUEIRA, 2011).

Identificados os temas pertinentes para a desconstrução, é necessário redigir um comentário temático para cada tema. Isto é, explica-se como determinado tema geral se aplica ao mini caso concreto. Deste modo, o aluno ao analisar mini casos de diferentes casos vai vendo como um mesmo tema se pode aplicar a diferentes situações (mini casos) (CARVALHO; PINTO; MONTEIRO, 2002, p. 2).

Uma vez realizada a desconstrução, estamos agora diante de um processo de reconstrução de conceitos. Pedro (2005) aponta como contribuição dos comentários temáticos o fato de eles permitirem relacionar vários temas na mesma situação, ressaltando a 
importância da consideração de múltiplas perspectivas de análise. Nesse sentido, eles favorecem o entendimento do mini caso.

Dentro de um conjunto de casos, mini casos e temas de análise conceitual, é possível (e muito provável) que um mesmo tema não se aplique apenas a uma situação, mas sim esteja relacionado a diversos mini casos e casos. Nesse sentido, a consideração de um único contexto de aplicação de um determinado conteúdo pode limitar a construção flexível de conhecimentos.

Assim, para a operacionalização da TFC, há dois processos que os autores consideram essenciais e complementares, associados à desconstrução e reconstrução de conceitos (SOUSA, 2004; ALEIXO, 2008). Um deles possibilita a desconstrução do caso em mini casos analisados a partir dos temas associados, através dos comentários temáticos. $\mathrm{O}$ outro percurso permite atravessar diversos mini casos e comentários temáticos para compreender como um determinado tema se aplica em casos e mini casos distintos. Esse último processo é denominado travessia temática (CARVALHO, 1998, 2000, 2011; MARQUES; CARVALHO; GUIMARÃES, 2004; REZENDE; COLA, 2004; PINHO, 2006). Nesse sentido, a construção flexível de conhecimentos ocorre por meio da constante desconstrução e reconstrução de conceitos.

Nesse contexto, as travessias temáticas permitem explicitar - através dos comentários temáticos - como um mesmo tema se aplica a um conjunto heterogêneo de mini casos de diferentes casos (CARVALHO et al., 2002; PEDRO, 2005; PINHO, 2006).

Pode-se dizer, então, que a flexibilidade exigida em situações de aplicação de conhecimento é bidimensional: por um lado, os casos precisam ser decompostos em diversos mini casos; por outro lado, é preciso estabelecer diversas ligações entre os mini casos de diferentes casos, através dos comentários e travessias temáticas, aproximando mini casos distintos. Será essa travessia pelos diferentes mini casos que estabelecerá caminhos para a reconstrução do conhecimento a ser aplicado para solucionar uma nova situação (CARVALHO, 2000; PINHO, 2006; ALEIXO, 2008).

Ainda, as travessias temáticas contribuem para estabelecer diversas ligações entre casos e mini casos e conceitos, de modo a construir estruturas de conhecimento flexíveis que favoreçam a reestruturação das mesmas em novos contextos (PEDRO, 2005; SPIRO; COLLINS; RAMCHANDRAN, 2007a; LEITE, 2011; VASCONCELOS; LEÃO, 2012; SOUZA; LEÃO, 2015).

\section{Metodologia}

Considerando os procedimentos técnicos utilizados para a coleta e análise dos dados, a pesquisa realizada pode ser classificada como bibliográfica (GIL, 2002).

Essa pesquisa bibliográfica foi realizada em publicações de periódicos das áreas de ensino e pesquisa em ensino Ciências. Os objetivos principais foram: (i) situar a flexibilidade 
cognitiva nas referidas áreas; e (ii) buscar subsídios para consubstanciar o desenvolvimento da flexibilidade cognitiva através da elaboração e avaliação de atividades didáticas de Física.

A busca pelos periódicos foi realizada na Plataforma Sucupira, base de referência do Sistema Nacional de Pós-Graduação. Nesta plataforma está disponível a consulta aos Periódicos Qualis².

O método de busca dos periódicos teve como filtros: 1) evento de classificação: classificações de periódicos quadriênio 2013-2016; 2) área de avaliação: ensino; 3) qualis A1, A2, B1 e B2; 4) áreas de ensino e pesquisa em ensino de Ciências. A justificativa para a escolha desses filtros foi a de selecionar periódicos bem avaliados nas áreas de ensino e pesquisa em ensino de Ciências.

Uma vez realizada a busca pelos periódicos, foi feita a seleção dos artigos. Para isso, foi utilizado o termo "flexibilidade cognitiva", além de suas respectivas traduções para outras línguas, em consonância com o periódico analisado. Os filtros foram título, resumo ou palavras-chave, de modo a selecionar artigos cuja ênfase estivesse na flexibilidade cognitiva.

Para pesquisar os artigos com os referidos termo e filtros, utilizamos o motor de busca contido em cada periódico. De modo a confirmar os resultados obtidos, utilizamos também, para cada periódico, uma ferramenta de pesquisa avançada do Google ${ }^{3}$, que consiste em inserir no motor de busca o seguinte: "termo a ser pesquisado" site:endereço eletrônico principal do periódico. Por exemplo, para pesquisar o termo flexibilidade cognitiva nos periódicos do Caderno Brasileiro de Ensino de Física (cujo endereço eletrônico é https://periodicos.ufsc.br/index.php/fisica), inserimos no motor de busca do Google o seguinte: "flexibilidade cognitiva" site:https://periodicos.ufsc.br/index.php/fisica.

A revisão bibliográfica abrangeu as publicações realizadas a partir do ano de 1990 até o final de 2017. A justificativa para a escolha do referido ano de início da busca foi a consonância com a proposição da TFC, que ocorreu no final da década de 80 (SPIRO; JEHNG, 1990).

Após a seleção dos artigos, se deu a leitura completa e análise dos mesmos. Essa análise foi realizada em duas etapas, em consonância com os referidos objetivos da revisão bibliográfica. A seguir, apresentamos e discutimos os resultados obtidos.

\section{Apresentação e discussão dos resultados}

\section{IV.1 Busca pelos periódicos}

A referida busca pelos periódicos resultou em trinta e três periódicos, listados no quadro 1.

\footnotetext{
$2<$ https://sucupira.capes.gov.br/sucupira/public/consultas/coleta/veiculoPublicacaoQualis/listaConsultaGeral Periodicos.jsf $>$.

$3<$ https://www.google.com.br/>.
} 
Quadro 1 - Listagem dos periódicos encontrados.

\begin{tabular}{|c|c|c|c|}
\hline & Qualis & Periódico & ISSN \\
\hline 1 & A1 & Research in Science Education & $0157-244 X$ \\
\hline 2 & A1 & American Journal of Physics & $0002-9505$ \\
\hline 3 & $\mathrm{~A} 1$ & Ciência \& Educação & $1980-850 X$ \\
\hline 4 & A1 & Enseñanza de las Ciencias & $0212-4521$ \\
\hline 5 & A1 & International Journal of Science Education & 0950-0693 \\
\hline 6 & A1 & Revista Brasileira de Ensino de Física & $1806-9126$ \\
\hline 7 & A1 & Revista de Educacion de las Ciencias & $0124-5481$ \\
\hline 8 & A1 & Science \& Education (Dordrecht) & 0926-7220 \\
\hline 9 & A1 & Ensaio: Pesquisa em Educação em Ciências & $1983-2117$ \\
\hline 10 & A1 & European Journal of Physics (Print) & 0143-0807 \\
\hline 11 & A1 & Science Education & $1098-237 X$ \\
\hline 12 & A2 & Investigações em Ensino de Ciências & $1518-8795$ \\
\hline 13 & A2 & Revista Electrónica de Enseñanza de las Ciencias (REEC) & $1579-1513$ \\
\hline 14 & A2 & Revista Brasileira de Pesquisa em Educação em Ciências & $1806-5104$ \\
\hline 15 & $\mathrm{~A} 2$ & Revista Electrónica de Investigación en Educación en Ciencias & $1850-6666$ \\
\hline 16 & $\mathrm{~A} 2$ & Alexandria (UFSC) & $1982-5153$ \\
\hline 17 & A2 & Caderno Brasileiro de Ensino de Física & $2175-7941$ \\
\hline 18 & A2 & Latin - American Journal of Physics Education & $1870-9095$ \\
\hline 19 & A2 & Revista Acta Scientiae & $2178-7727$ \\
\hline 20 & A2 & Revista Brasileira de Ensino de Ciência e Tecnologia & $1982-873 X$ \\
\hline 21 & A2 & Dynamis (FURB. Online) & $1982-4866$ \\
\hline 22 & B1 & Alambique (Barcelona) & $1133-9837$ \\
\hline 23 & B1 & Ciência \& Ensino (Online) & $1980-8631$ \\
\hline
\end{tabular}




\begin{tabular}{|c|c|l|c|}
\cline { 2 - 4 } \multicolumn{1}{l|}{} & Qualis & \multicolumn{1}{|c|}{ Periódico } & ISSN \\
\hline 24 & B1 & Experiências em Ensino de Ciências (UFRGS) & $1982-2413$ \\
\hline 25 & B1 & Gondola: ensenanza y aprendizaje de las ciencias & $2145-4981$ \\
\hline 26 & B1 & Revista Ciências \& Idéias & $2176-1477$ \\
\hline 27 & B1 & Revista de Enseñanza de la Física & $0326-7091$ \\
\hline 28 & B1 & Science Education International (Online) & $2077-2327$ \\
\hline 29 & B1 & Revista Eletrônica Debates em Educação Científica e Tecnológica & $2236-2150$ \\
\hline 30 & B2 & A Física na Escola & $1983-6430$ \\
\hline 31 & B2 & Ciência e Natura & $2179-460 X$ \\
\hline 32 & ----- & European Journal of Physics Education & $1309-7202$ \\
\hline 33 & ----- & Journal of Research in Science Teaching & $1098-2736$ \\
\hline
\end{tabular}

Mesmo não constando na classificação do qualis, foram acrescentadas as revistas European Journal of Physics Education e Journal of Research in Science Teaching, tendo em vista a importância que possuem para as referidas áreas de interesse dessa revisão bibliográfica.

\section{IV.2 Seleção dos artigos}

A seleção dos artigos, utilizando a metodologia descrita no item anterior, resultou num total de 26 artigos. Enfatizamos a pequena quantidade de artigos encontrada, considerando que foram analisadas as publicações de trinta e três periódicos em um intervalo de tempo de vinte e sete anos. Isso mostra que a flexibilidade cognitiva ainda é pouco trabalhada no âmbito do ensino de Ciências, o que também explicita a relevância e necessidade de ampliação das investigações sobre a temática.

Para visualizarmos melhor como a quantidade de artigos publicados com ênfase em flexibilidade cognitiva se alterou no referido período, construímos o gráfico do ano de publicação versus quantidade de artigos encontrada (Fig. 1).

Analisando esse gráfico, é possível notar que o primeiro artigo encontrado foi publicado no ano de 1998, cerca de dez anos após a proposição da Teoria da Flexibilidade Cognitiva, que ocorreu no final da década de 1980. De certa forma, este resultado já era esperado, tendo em vista o intervalo de tempo necessário para o desenvolvimento e publicação dos primeiros trabalhos sobre a temática na área de ensino e pesquisa em ensino de Ciências. Além disso, destacamos que a maior quantidade de artigos publicados ocorreu 
nos últimos doze anos (de 2006 a 2017). Isso mostra que a flexibilidade cognitiva vem, aos poucos, crescendo como temática de pesquisa na referida área.

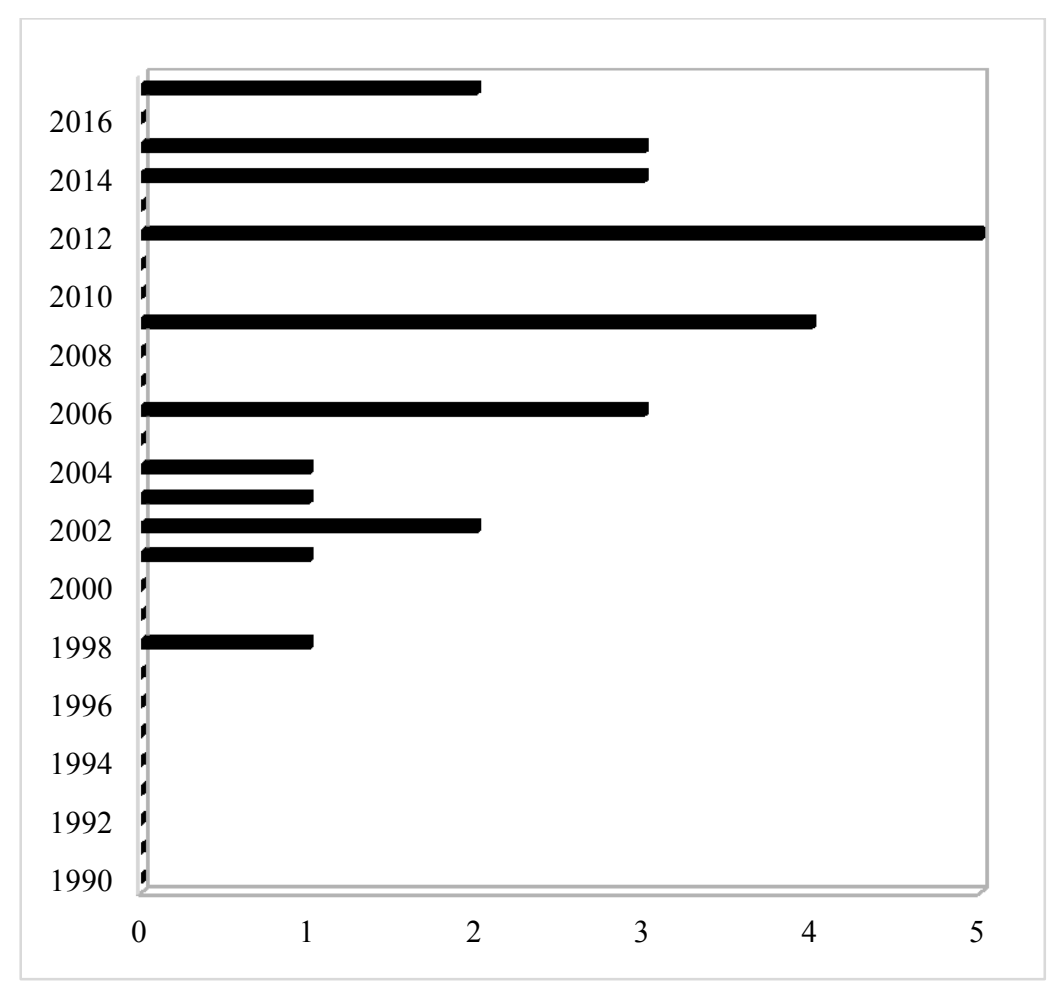

Fig. 1 - Quantidade de artigos encontrada em cada ano.

O quadro 2 ilustra o título, o periódico de publicação e o(s) autor(es) dos artigos encontrados.

Quadro 2 - Listagem dos artigos encontrados.

\begin{tabular}{|c|c|c|c|}
\hline $\mathbf{N}^{\mathbf{0}}$ & Título & Periódico & Autores \\
\hline 1 & $\begin{array}{c}\text { O processo de construção da FlexQuest por } \\
\text { professores de ciências: análise de alguns saberes } \\
\text { necessários }\end{array}$ & Ciência e Educação & $\begin{array}{c}\text { SOUZA e LEÃO } \\
(2015)\end{array}$ \\
\hline 2 & $\begin{array}{c}\text { FlexQuest: una webquest con aportes de la Teoria de } \\
\text { la Flexibilidad Cognitiva (TFC) }\end{array}$ & $\begin{array}{c}\text { Enseñanza de las } \\
\text { Ciencias }\end{array}$ & LEÃO e NERI (2009) \\
\hline 3 & $\begin{array}{c}\text { Educativo en el Dominio de la Eseñanza de la Física } \\
\text { que Concilie el Modelo del Negocio con las Mejores } \\
\text { Prácticas de las Ciencias de La Computación }\end{array}$ & $\begin{array}{c}\text { Enseñanza de las } \\
\text { Ciencias }\end{array}$ & ESTEVES e \\
\hline
\end{tabular}




\begin{tabular}{|c|c|c|c|}
\hline $\mathbf{N}^{\mathbf{0}}$ & Título & Periódico & Autores \\
\hline 4 & $\begin{array}{l}\text { From conceptual development to science education: a } \\
\text { psychological point of view }\end{array}$ & $\begin{array}{l}\text { International } \\
\text { Journal of Science } \\
\text { Education }\end{array}$ & $\begin{array}{c}\text { VOSNIADOU e } \\
\text { LOANNIDES (1998) }\end{array}$ \\
\hline 5 & $\begin{array}{c}\text { As novas tecnologias na prática pedagógica sob a } \\
\text { perspectiva construtivista }\end{array}$ & $\begin{array}{l}\text { Ensaio: Pesquisa } \\
\text { em Educação em } \\
\text { Ciências }\end{array}$ & REZENDE (2002) \\
\hline 6 & $\begin{array}{l}\text { Hipermídia na educação: flexibilidade cognitiva, } \\
\text { interdisciplinaridade e complexidade }\end{array}$ & $\begin{array}{l}\text { Ensaio: Pesquisa } \\
\text { em Educação em } \\
\text { Ciências }\end{array}$ & $\begin{array}{l}\text { REZENDE e COLA } \\
\text { (2004) }\end{array}$ \\
\hline 7 & $\begin{array}{l}\text { Informática na educação matemática e científica dos } \\
\text { anos iniciais de escolaridade: um estudo sobre as } \\
\text { pesquisas da área Ensino de Ciências e Matemática }\end{array}$ & $\begin{array}{l}\text { Ensaio: Pesquisa } \\
\text { em Educação em } \\
\text { Ciências }\end{array}$ & $\begin{array}{l}\text { FRAIHA-MARTINS } \\
\text { e GONÇALVES } \\
\text { (2012) }\end{array}$ \\
\hline 8 & $\begin{array}{c}\text { Uma revisão bibliográfica sobre a } \\
\text { interdisciplinaridade no Ensino das Ciências da } \\
\text { Natureza }\end{array}$ & $\begin{array}{l}\text { Ensaio: Pesquisa } \\
\text { em Educação em } \\
\text { Ciências }\end{array}$ & $\begin{array}{c}\text { MOZENA e } \\
\text { OSTERMANN } \\
(2014)\end{array}$ \\
\hline 9 & $\begin{array}{c}\text { Problem-Based Learning: Using Ill-Structured } \\
\text { Problems in Biology Project Work }\end{array}$ & Science Education & CHIN e CHIA (2006) \\
\hline 10 & $\begin{array}{c}\text { Long-Term Self-Regulation of Biology Learning } \\
\text { Using Standard Junior High School Science } \\
\text { Curriculum }\end{array}$ & Science Education & $\begin{array}{l}\text { EILAM e REITER } \\
\qquad(2014)\end{array}$ \\
\hline 11 & $\begin{array}{l}\text { Organização do conhecimento, construção de } \\
\text { hiperdocumentos e ensino das ciências da terra }\end{array}$ & $\begin{array}{l}\text { Investigações em } \\
\text { Ensino de Ciências }\end{array}$ & $\begin{array}{c}\text { BOLACHA e } \\
\text { AMADOR (2003) }\end{array}$ \\
\hline 12 & $\begin{array}{c}\text { Desenvolvimento e avaliação de um sistema } \\
\text { hipermídia que integra conceitos básicos de mecânica, } \\
\text { biomecânica e anatomia humana }\end{array}$ & $\begin{array}{l}\text { Investigações em } \\
\text { Ensino de Ciências }\end{array}$ & $\begin{array}{l}\text { REZENDE, GARCIA } \\
\text { e COLA (2006) }\end{array}$ \\
\hline 13 & $\begin{array}{l}\text { Utilização de recursos audiovisuais em uma estratégia } \\
\text { Flexquest sobre radioatividade }\end{array}$ & $\begin{array}{l}\text { Investigações em } \\
\text { Ensino de Ciências }\end{array}$ & $\begin{array}{l}\text { VASCONCELOS e } \\
\text { LEÃO (2012) }\end{array}$ \\
\hline 14 & $\begin{array}{l}\text { Experimental activities based on ill-structured } \\
\text { problems improve Brazilian school students' } \\
\text { understanding of the nature of scientific knowledge }\end{array}$ & $\begin{array}{l}\text { Revista Electrónica } \\
\text { de Enseñanza de las } \\
\text { Ciencias (REEC) }\end{array}$ & $\begin{array}{l}\text { FOLMER et al. } \\
\qquad(2009)\end{array}$ \\
\hline 15 & $\begin{array}{l}\text { Trabalho colaborativo no ensino de Física mediado } \\
\text { por tecnologias educacionais em rede para resolução } \\
\text { de problemas }\end{array}$ & $\begin{array}{l}\text { Revista Electrónica } \\
\text { de Enseñanza de las } \\
\text { Ciencias (REEC) }\end{array}$ & $\begin{array}{l}\text { JOSÉ e DE BASTOS } \\
\text { (2017) }\end{array}$ \\
\hline
\end{tabular}




\begin{tabular}{|c|c|c|c|}
\hline $\mathbf{N}^{\mathbf{0}}$ & Título & Periódico & Autores \\
\hline 16 & $\begin{array}{l}\text { Pesquisas em periódicos nacionais e internacionais } \\
\text { sobre o ensino e aprendizagem de ligação química }\end{array}$ & $\begin{array}{l}\text { Revista Brasileira } \\
\text { de Pesquisa em } \\
\text { Educação em } \\
\text { Ciências }\end{array}$ & $\begin{array}{l}\text { FERNANDES e } \\
\text { CAMPOS (2012) }\end{array}$ \\
\hline 17 & $\begin{array}{l}\text { Flexibilidade cognitiva e hipermídia educacional na } \\
\text { formação inicial de físicos-educadores }\end{array}$ & $\begin{array}{l}\text { Revista Brasileira } \\
\text { de Pesquisa em } \\
\text { Educação em } \\
\text { Ciências }\end{array}$ & $\begin{array}{l}\text { VIDMAR, DE } \\
\text { BASTOS e ABEGG } \\
\text { (2014) }\end{array}$ \\
\hline 18 & $\begin{array}{c}\text { Desenvolvimento e avaliação de um sistema } \\
\text { hipermídia para facilitar a reestruturação conceitual } \\
\text { em mecânica básica }\end{array}$ & $\begin{array}{l}\text { Caderno Brasileiro } \\
\text { de Ensino de Física }\end{array}$ & REZENDE (2001) \\
\hline 19 & $\begin{array}{l}\text { Padrões de navegação em um sistema hipermídia de } \\
\text { mecânica básica }\end{array}$ & $\begin{array}{l}\text { Caderno Brasileiro } \\
\text { de Ensino de Física }\end{array}$ & $\begin{array}{l}\text { REZENDE, SOUSA } \\
\text { e BARROS (2012) }\end{array}$ \\
\hline 20 & $\begin{array}{l}\text { Contribuição da Web } 2.0 \text { como ferramenta de } \\
\text { aprendizagem: um estudo de caso }\end{array}$ & $\begin{array}{l}\text { Revista Brasileira } \\
\text { de Ensino de } \\
\text { Ciência e } \\
\text { Tecnologia }\end{array}$ & $\begin{array}{l}\text { LEITE e LEÃO } \\
\qquad(2015)\end{array}$ \\
\hline 21 & $\begin{array}{c}\text { Ensino de Física: Investigando os Benefícios da } \\
\text { Mediação Tecnológica Educacional }\end{array}$ & Dynamis & ABEGG et al. (2012) \\
\hline 22 & $\begin{array}{l}\text { Contribuições da hipermídia educacional para o } \\
\text { desenvolvimento de Atividades de Estudo de Física }\end{array}$ & $\begin{array}{l}\text { Revista de } \\
\text { Enseñanza de la } \\
\text { Física }\end{array}$ & $\begin{array}{l}\text { VIDMAR et al. } \\
\qquad(2015)\end{array}$ \\
\hline 23 & $\begin{array}{l}\text { Aprendizaje avanzado: comprensión del concepto de } \\
\text { "invariancia" a partir de textos }\end{array}$ & $\begin{array}{l}\text { Revista de } \\
\text { Enseñanza de la } \\
\text { Física }\end{array}$ & $\begin{array}{l}\text { HOYOS e POCOVÍ } \\
\text { (2017) }\end{array}$ \\
\hline 24 & $\begin{array}{l}\text { Media-assisted Learning in Science Education: An } \\
\text { Interdisciplinary Approach to Hibernation and Energy } \\
\text { Transfer }\end{array}$ & $\begin{array}{l}\text { Science Education } \\
\text { International }\end{array}$ & $\begin{array}{l}\text { GIRWIDZ et al. } \\
\qquad(2006)\end{array}$ \\
\hline 25 & $\begin{array}{c}\text { Situational Knowledge in Physics: The Case of } \\
\text { Electrodynamics }\end{array}$ & $\begin{array}{l}\text { Journal of Research } \\
\text { in Science Teaching }\end{array}$ & $\begin{array}{c}\text { SAVELSBERGH, DE } \\
\text { JONG e } \\
\text { FERGUSON- } \\
\text { HESSLER (2002) }\end{array}$ \\
\hline 26 & $\begin{array}{l}\text { Promoting Complex Systems Learning through the } \\
\text { Use of Conceptual Representations in Hypermedia }\end{array}$ & $\begin{array}{l}\text { Journal of Research } \\
\text { in Science Teaching }\end{array}$ & $\begin{array}{l}\text { LIU e HMELO- } \\
\text { SILVER (2009) }\end{array}$ \\
\hline
\end{tabular}




\title{
IV.3 Leitura e análise dos artigos selecionados
}

A próxima etapa de nossa revisão bibliográfica consistiu na leitura completa e análise dos vinte e seis artigos encontrados. Ao longo do processo de busca dos artigos nos periódicos, surgiram dúvidas em alguns dos referidos artigos em relação à ênfase ou não na flexibilidade cognitiva. Através dessa leitura, foi possível constatar que oito ${ }^{4}$ dos vinte e seis artigos inicialmente selecionados não possuíam ênfase na flexibilidade cognitiva, de modo que esses não fizeram parte das próximas etapas da revisão.

Assim, foram analisados um total de dezoito artigos. Conforme mencionamos anteriormente, os objetivos principais dessa análise foram: (i) situar a flexibilidade cognitiva nas áreas de ensino e pesquisa em ensino de Ciências; e (ii) buscar subsídios para consubstanciar o desenvolvimento da flexibilidade cognitiva através da elaboração e avaliação de atividades didáticas de Física. Neste sentido, organizamos a análise dos artigos em duas etapas: etapa 1 , associada ao objetivo (i), e etapa 2 , associada ao objetivo (ii).

\section{IV.3.1 Etapa 1}

$\mathrm{Na}$ etapa 1, buscamos verificar a natureza ${ }^{5}$ dos trabalhos encontrados. Para isso, elaboramos o seguinte questionamento, que norteou a leitura dos artigos: 1) Qual a natureza dos trabalhos com ênfase na flexibilidade cognitiva nas áreas de ensino e pesquisa em ensino de Ciências?

Dessa análise emergiram as seguintes categorias, relacionadas ao referido questionamento:

1) Desenvolvimento, implementação e/ou avaliação de sistema hipermídia: artigos cujo foco principal consistiu em desenvolver sistemas hipermídia e, em alguns casos, implementar e avaliar os referidos sistemas. $\mathrm{O}$ artigo a seguir exemplifica o foco desta categoria.

\begin{abstract}
Este trabalho descreve a modelagem de um sistema hipermídia de aprendizagem que integra conceitos físicos, biomecânicos e anatômicos envolvidos no movimento humano (denominado de "Biomec") e um estudo realizado a partir de sua utilização por estudantes universitários. $O$ desenho instrucional do sistema hipermídia "Biomec" foi elaborado de maneira a aproximar suas características a um referencial teórico que articula Teoria da Flexibilidade Cognitiva (TFC) à abordagem interdisciplinar do conhecimento. O sistema foi avaliado a partir de sua utilização por estudantes das disciplinas de Biomecânica I e Cinesiologia de um curso de licenciatura em Educação Física. [...] O conjunto de dados obtidos permitiu concluir que o sistema desenvolvido é um material educativo relevante, capaz de influenciar positivamente a atitude dos alunos em relação à Física e
\end{abstract}

\footnotetext{
${ }^{4}$ SAVELSBERGH, DE JONG; FERGUSON-HESSLER, 2002; CHIN; CHIA, 2006; ESTEVES; GUIILLÉN, 2009; FOLMER et al., 2009; FERNANDES; CAMPOS, 2012; FRAIHA-MARTINS; GONÇALVES, 2012; EILAM; REITER, 2014; MOZENA; OSTERMANN, 2014.

5 Entendemos natureza como associada ao foco dos trabalhos analisados.
} 
favorecer a abordagem interdisciplinar do movimento humano e que parece atender melhor aos estudantes de Biomecânica I do que os de Cinesiologia (REZENDE; GARCIA; COLA, 2006, p. 1).

2) Elaboração, implementação e/ou avaliação de atividade: artigos cujo foco principal consistiu em propor atividades e, em alguns casos, implementá-las e avaliá-las. Diferenciamse da categoria anterior pelo fato de não desenvolverem o recurso didático utilizado. $\mathrm{O}$ artigo a seguir exemplifica o foco desta categoria.

O processo produtivo-colaborativo, mediado pelo Wiki do Moodle, gerou atividades de estudo mediadas por hipermídia educacionais em Física compostas por hipertextos, imagens, animações e simulações. Nossos resultados indicam que atividades de estudo em Física, mediadas por hipermídia educacional, têm potencial inovador para a produção escolar colaborativa e iniciação à docência, contribuindo para um ensino-aprendizagem mais dinâmico, menos expositivo e, portanto, mais interessante na visão dos estudantes (ABEGG et al., 2012, p. 2).

Visando gerar processos realmente inovadores de ensino de Física, que integrem professores e estudantes, desenvolvemos colaborativamente planejamentos escolares (compreendidos como atividades de estudo extracurriculares) mediados por hipermídias educacionais disponíveis em portais para professores na Internet. (ABEGG et al., 2012, p. 3).

3) Abordagem de aspectos teóricos: artigos cujo foco principal consistiu em apresentar discussões e contribuições teóricas sobre uma temática específica, sejam elas exclusivamente teóricas ou oriundas de dados empíricos. Difere-se das categorias anteriores pelo fato de não apresentar propostas de recurso didático e atividade. O artigo a seguir exemplifica o foco desta categoria.

Este artigo apresenta os resultados de uma investigação que objetivou analisar alguns saberes necessários ao processo de construção da estratégia FlexQuest (FQ) por professores de ciências. [...] Eles relataram algumas dificuldades encontradas, e indicaram alguns saberes demandados no processo. A partir dos relatos e da categorização de Shulman sobre saberes docentes, são indicadas algumas necessidades formativas para o trabalho com a FQ (SOUZA; LEÃO, 2015, p. 1).

A tabela 1 ilustra a quantidade de artigos encontrada para cada categoria, bem como os autores destes artigos.

Analisando a tabela 1, destacamos que a maior parte dos artigos tem como foco o desenvolvimento, implementação e/ou avaliação de sistema hipermídia. É importante salientar ainda que a menor parte dos artigos está relacionada à elaboração, implementação e/ou avaliação de atividade, o qual estamos justamente buscando subsídios para consubstanciar o desenvolvimento da flexibilidade cognitiva. 
Tabela 1 - Categorização dos artigos encontrados quanto à natureza ${ }^{6}$.

\begin{tabular}{|l|c|l|}
\hline \multicolumn{1}{|c|}{ Categoria } & $\begin{array}{l}\text { Qtde de } \\
\text { artigos }\end{array}$ & \multicolumn{1}{|c|}{ Autores } \\
\hline $\begin{array}{l}\text { 1. Desenvolvimento, } \\
\text { implementação e/ou avaliação de } \\
\text { sistema hipermídia }\end{array}$ & 9 & $\begin{array}{l}\text { REZENDE (2001), BOLACHA e AMADOR (2003), } \\
\text { REZENDE e COLA (2004), GIRWIDZ et al. (2006), } \\
\text { REZENDE, GARCIA e COLA (2006), LEÃO e NERI } \\
\text { (2009), LIU e HMELO-SILVER (2009), REZENDE, } \\
\text { SOUSA e BARROS (2012), VASCONCELOS e LEÃO } \\
\text { (2012). }\end{array}$ \\
\hline $\begin{array}{l}\text { 2. Elaboração, implementação e/ou } \\
\text { avaliação de atividade }\end{array}$ & 3 & $\begin{array}{l}\text { ABEGG et al. (2012), VIDMAR, DE BASTOS e ABEGG } \\
\text { (2014), JOSÉ e DE BASTOS (2017). }\end{array}$ \\
\hline 3. Abordagem de aspectos teóricos & 8 & $\begin{array}{l}\text { VOSNIADOU e LOANNIDES (1998), REZENDE (2002), } \\
\text { REZENDE e COLA (2004), LEITE e LEÃO (2015), } \\
\text { SOUZA e LEÃO (2015), VIDMAR, DE BASTOS e } \\
\text { ABEGG (2014), VIDMAR et al. (2015), HOYOS e } \\
\text { POCOVÍ (2017). }\end{array}$ \\
\hline
\end{tabular}

Por fim, enfatizamos também que não encontramos artigos de revisão de literatura sobre flexibilidade cognitiva no ensino Ciências, de modo que nossa pesquisa bibliográfica se mostra pertinente neste contexto.

\section{IV.3.2 Etapa 2}

$\mathrm{Na}$ etapa 2, analisamos especificamente os doze artigos que continham propostas de recurso didático ou atividade (categorias 1 e 2 da etapa 1). O objetivo principal foi buscar subsídios para a elaboração e avaliação de atividades didáticas de Física, tendo em vista consubstanciar o desenvolvimento da flexibilidade cognitiva.

Para analisarmos os referidos artigos, elaboramos os seguintes questionamentos: 1) Em que nível(is) de ensino a flexibilidade cognitiva é trabalhada no âmbito do ensino de Ciências?; 2) Qual(is) a(s) temática(s) das propostas que abordam a flexibilidade cognitiva no âmbito do ensino de Ciências?; 3) Qual(is) o(s) recurso(s) didático(s) utilizado(s) nas propostas que abordam a flexibilidade cognitiva no âmbito do ensino de Ciências?; 4) Qual(is) metodologia(s) de ensino utilizada(s) nas propostas que abordam a flexibilidade cognitiva no âmbito do ensino de Ciências?; 5) Qual(is) o(s) instrumento(s) utilizado(s) para avaliar a aprendizagem nas propostas que abordam a flexibilidade cognitiva no âmbito do

\footnotetext{
6 É possível notar que a soma dos artigos excede o total de dezoito. Isto ocorre pelo fato de que identificamos mais de um foco principal no artigo de Rezende e Cola (2004) e de Vidmar, de Bastos e Abegg (2014).
} 
ensino de Ciências?; 6) Como a aprendizagem é avaliada nas propostas que abordam a flexibilidade cognitiva no âmbito do ensino de Ciências?

Apresentamos a seguir a análise dos artigos, organizada separadamente para cada questionamento. Cabe sublinhar que os termos utilizados para denominar as categorias obtidas foram aqueles presentes nos artigos analisados.

\section{IV.3.2.1 Nível de ensino}

Da análise dos artigos, em relação ao questionamento 1, emergiram os seguintes grupos: 1) Ensino Médio; 2) Ensino Superior; 3) Não explicita.

A tabela 2 ilustra a quantidade de artigos encontrada para cada grupo, bem como os autores destes artigos.

Tabela 2 - Agrupamento dos artigos quanto ao nível de ensino? ${ }^{7}$

\begin{tabular}{|l|c|l|}
\hline \multicolumn{1}{|c|}{ Grupo } & $\begin{array}{c}\text { Qtde de } \\
\text { artigos }\end{array}$ & \multicolumn{1}{|c|}{ Autores } \\
\hline 1. Ensino Médio & 6 & $\begin{array}{l}\text { BOLACHA e AMADOR (2003), GIRWIDZ et al. (2006), LEÃO e } \\
\text { NERI (2009), LIU e HMELO-SILVER (2009), ABEGG } \text { et al. } \\
\text { (2012), VASCONCELOS e LEÃO (2012) }\end{array}$ \\
\hline 2. Ensino Superior & 6 & $\begin{array}{l}\text { REZENDE (2001), REZENDE, GARCIA e COLA (2006), LIU e } \\
\text { (2012), VIDMAR, DE BASTOS e ABEGG (2014), JOSÉ e de } \\
\text { BASTOS (2017). }\end{array}$ \\
\hline 3. Não explicita & 1 & REZENDE e COLA (2004) \\
\hline
\end{tabular}

Analisando a tabela 2, identificamos que a quantidade de propostas voltada ao Ensino Médio é idêntica à quantidade de propostas voltadas ao Ensino Superior. Consideramos importante salientar a inexistência de trabalhos voltados ao Ensino Fundamental, o que atribuímos ao fato de o foco de aplicação da TFC estar especificamente na construção de conhecimentos de nível avançado (SPIRO et al., 1988; SPIRO; JEHNG, 1990; CARVALHO, 1998, 2000; PINHO, 2006).

\footnotetext{
${ }^{7}$ É possível notar que a soma dos artigos excede o total de doze. Isto ocorre pelo fato de que identificamos mais de um nível de ensino no artigo de Liu e Hmelo-Silver (2009).
} 


\section{IV.3.2.2 Temática}

$\mathrm{Da}$ análise dos artigos, em relação ao questionamento 2, emergiram os seguintes grupos: 1) Mecânica; 2) Termodinâmica; 3) Eletrostática; 4) Radioatividade; 5) Biomecânica; 6) Fisiologia humana; 7) Anatomia humana; 8) Não explicita.

A tabela 3 ilustra a quantidade de artigos encontrada para cada grupo, bem como os autores desses artigos.

Tabela 3 - Agrupamento dos artigos quanto à temática ${ }^{8}$.

\begin{tabular}{|l|c|l|}
\hline \multicolumn{1}{|c|}{ Grupo } & $\begin{array}{c}\text { Qtde de } \\
\text { artigos }\end{array}$ & \multicolumn{1}{|c|}{ Autores } \\
\hline 1. Mecânica & 3 & $\begin{array}{l}\text { REZENDE (2001), REZENDE, GARCIA e COLA } \\
(2006), \text { REZENDE, SOUSA e BARROS (2012) }\end{array}$ \\
\hline 2. Termodinâmica & 2 & GIRWIDZ et al. (2006), JOSÉ e DE BASTOS (2017). \\
\hline 3. Eletrostática & 1 & ABEGG et al. (2012) \\
\hline 4. Radioatividade & 1 & VASCONCELOS e LEÃO (2012) \\
\hline 5. Biomecânica & 2 & $\begin{array}{l}\text { REZENDE e COLA (2004), REZENDE, GARCIA e } \\
\text { COLA (2006) }\end{array}$ \\
\hline 6. Fisiologia humana & 2 & LEÃO e NERI (2009), LIU e HMELO-SILVER (2009) \\
\hline 7. Anatomia humana & 1 & REZENDE, GARCIA e COLA (2006) \\
\hline
\end{tabular}

Analisando a tabela 3, identificamos que a maior parte das propostas aborda temáticas relacionadas ao ensino de Física, sendo a Mecânica a temática mais frequente, predominância essa que é também observada nos trabalhos da área de ensino e pesquisa em ensino de Física, de modo geral.

Destacamos que as temáticas apresentadas na tabela 3 são complexas, o que consiste no foco de aplicação da TFC (SPIRO et al., 1988; SPIRO; JEHNG, 1990; CARVALHO, 1998, 2000; PINHO, 2006). Isso porque diversos aspectos são necessários para a sua compreensão, além de envolver a aplicação prática de conhecimentos (HEIDRICH, 2009).

\footnotetext{
${ }^{8}$ É possível notar que a soma dos artigos excede o total de doze. Isto ocorre pelo fato de que identificamos mais de uma temática no artigo de Rezende, Garcia e Cola (2006).
} 
Ainda, as temáticas estão associadas a situações concretas, de modo que possibilitam sua abordagem a partir de casos e mini casos (SPIRO; JEHNG, 1990; CARVALHO, 2000).

\section{IV.3.2.3 Recurso didático}

Da análise dos artigos, em relação ao questionamento 3, emergiram os seguintes grupos: 1) Hipermídia; 2) Simulação computacional.

A tabela 4 ilustra a quantidade de artigos encontrada para cada grupo, bem como os autores destes artigos.

Analisando a tabela 4, identificamos que a maior parte - quase que na totalidade das propostas utilizou como recurso didático a hipermídia.

Tabela 4 - Agrupamento dos artigos quanto ao recurso didático.

\begin{tabular}{|l|c|l|}
\hline Grupo & $\begin{array}{l}\text { Qtde de } \\
\text { artigos }\end{array}$ & \multicolumn{1}{|c|}{ Autores } \\
\hline 1. Hipermídia & 11 & $\begin{array}{l}\text { REZENDE, GARCIA e COLA (2006), LEÃO e NERI } \\
\text { (2009), LIU e HMELO-SILVER (2009), REZENDE, } \\
\text { REZENDE e COLA (2004), GIRWIDZ et al. (2006), } \\
\text { LẼ̃O (2012), VIDMAR, DE BASTOS e ABEGG } \\
\text { 2014), JOSÉ e de BASTOS (2017). }\end{array}$ \\
\hline 2. Simulação computacional & 1 & ABEGG et al. (2012) \\
\hline
\end{tabular}

De acordo com Spiro e Jehng (1990), os conhecimentos precisam ser representados de diferentes maneiras e organizados de modo a permitir diversas ligações entre eles, favorecendo assim o desenvolvimento da flexibilidade cognitiva. Nesse sentido, atribuímos a predominância da hipermídia como recurso didático à potencialidade da mesma para proporcionar essas múltiplas representações do conhecimento (SPIRO; JEHNG, 1990), o que a torna o principal recurso didático para implementação da TFC (BOLACHA; AMADOR, 2003; LEÃO; SOUZA; MOREIRA, 2011).

Embora com menor potencialidade que a hipermídia, destacamos que a simulação computacional - tal como a utilizada por Abegg et al. (2012) - também apresenta características, como interatividade e flexibilidade (ARANTES; MIRANDA; STUDART, 2010), que podem contribuir para o desenvolvimento da flexibilidade cognitiva. 


\section{IV.3.2.4 Metodologia de ensino}

Da análise dos artigos, em relação ao questionamento 4, identificamos diversas metodologias de ensino associadas aos referidos recursos didáticos. São elas: 1) Situaçãoproblema; 2) Situação física9; 3) Caso e mini-caso; 4) Múltiplas representações do conhecimento; 5) Ligação entre conceitos; 6) Comentário temático; 7) Travessia temática; 8) Aplicação do conhecimento.

A tabela 5 ilustra a quantidade de artigos encontrada para cada grupo, bem como os autores destes artigos.

Tabela 5 - Agrupamento dos artigos quanto à metodologia de ensino ${ }^{10}$.

\begin{tabular}{|l|c|l|}
\hline \multicolumn{1}{|c|}{ Grupo } & $\begin{array}{r}\text { Qtde de } \\
\text { artigos }\end{array}$ & \multicolumn{1}{|c|}{ Autores } \\
\hline 1. Situação-problema & 8 & $\begin{array}{l}\text { BOLACHA e AMADOR (2003), REZENDE, GARCIA e } \\
\text { SOLA (2006), LEÃO e NERI (2009), LIU e HMELO- } \\
\text { SEVE (2009), ABEGG et al. (2012). VASCONCELOS e } \\
\text { JOSÉ e DE BASTOS (2017) }\end{array}$ \\
\hline 3. Caso e mini-caso & 2 & REZENDE (2001), REZENDE, SOUSA e BARROS (2012) \\
\hline 2. Situação física & 4 & $\begin{array}{l}\text { REZENDE e COLA (2004), LEÃO e NERI (2009), } \\
\text { VASCONCELOS e LEÃO (2012), VIDMAR, DE BASTOS e } \\
\text { ABEGG (2014) }\end{array}$ \\
\hline $\begin{array}{l}\text { 4. Múltiplas representações do } \\
\text { conhecimento }\end{array}$ & 2 & $\begin{array}{l}\text { REZENDE, GARCIA e COLA (2006), LIU e HMELO- } \\
\text { SILVER (2009) }\end{array}$ \\
\hline 5. Ligação entre conceitos & 3 & $\begin{array}{l}\text { REZENDE (2001), GIRWIDZ et al. (2006), REZENDE, } \\
\text { SOUSA e BARROS (2012) }\end{array}$ \\
\hline 6. Comentário temático & 6 & $\begin{array}{l}\text { REZENDE (2001), GIRWIDZ et al. (2006), REZENDE, } \\
\text { ABEGG et al. (2012), REZENDE, SOUSA e BARROS } \\
\text { (2012) }\end{array}$ \\
\hline 7. Travessia temática & 2 & LEÃO e NERI (2009), VASCONCELOS e LEÃO (2012) \\
\hline
\end{tabular}

${ }^{9}$ Por exemplo: queda livre, lançamento vertical, lançamento horizontal e lançamento oblíquo (REZENDE, 2001; REZENDE; SOUSA; BARROS, 2012).

10 É possível notar que a soma dos artigos excede o total de doze. Isto ocorre pelo fato de que identificamos mais de uma metodologia de ensino no artigo de Rezende (2001), Girwidz et al. (2006), Rezende, Garcia e Cola (2006), Leão e Neri (2009), Liu e Hmelo-Silver (2009), Abegg et al. (2012), Rezende, Sousa e Barros (2012), Vasconcelos e Leão (2012), Vidmar, de Bastos e Abegg (2014). 


\begin{tabular}{|c|c|l|}
\hline Grupo & $\begin{array}{c}\text { Qtde de } \\
\text { artigos }\end{array}$ & \multicolumn{1}{|c|}{ Autores } \\
\hline 8. Aplicação do conhecimento & 3 & $\begin{array}{l}\text { GIRWIDZ et al. (2006), LEÃO e NERI (2009), LIU e } \\
\text { HMELO-SILVER (2009) }\end{array}$ \\
\hline
\end{tabular}

Analisando a tabela 5, identificamos que a maior parte das propostas abordou os conhecimentos científicos a partir de situações-problema, apresentando problemas a serem resolvidos que estão relacionados a situações concretas aos estudantes. Cabe sublinhar a coerência dessa abordagem com a estrutura principal da TFC.

Outra metodologia de ensino muito presente foi o que Spiro e Jehng (1990) denominam comentário temático, que consiste em explicitar as diversas formas de aplicação de um determinado conceito (tema) a uma dada situação concreta (mini caso) (SPIRO; JEHNG, 1990; REZENDE; COLA, 2004; SOUSA, 2004; PEDRO, 2005; PINHO, 2006; MOREIRA; PEDRO; NOGUEIRA, 2011). Entendemos esse como um ponto positivo a ser destacado, uma vez que os comentários temáticos permitem reconstruir conceitos, bem como relacionar vários temas na mesma situação (PEDRO, 2005), aspectos essenciais para o desenvolvimento da flexibilidade cognitiva.

Em relação às metodologias de ensino menos presentes nas propostas, citamos a travessia temática que, no âmbito da TFC, consiste em explicitar como um mesmo conceito (tema) se aplica a um conjunto heterogêneo de situações concretas (mini casos de diferentes casos) (CARVALHO et al., 2002; PEDRO, 2005; PINHO, 2006). A pouca ocorrência das travessias temáticas nos artigos analisados é um ponto negativo, uma vez que elas são fundamentais para a construção de estruturas de conhecimento flexíveis que favoreçam a reestruturação das mesmas em novos contextos.

Outro aspecto pouco explorado nos artigos, de modo geral, foi a aplicação do conhecimento, que se refere à utilização de um conceito científico em contexto(s) distinto(s) daquele no qual ele foi inicialmente abordado, e que está diretamente associado ao conceito de flexibilidade cognitiva.

Consideramos importante destacar também que os elementos que constituem a estrutura principal da $\mathrm{TFC}^{11}$ estiveram, de alguma forma, presentes nas propostas analisadas.

\section{IV.3.2.5 Instrumento de avaliação}

Da análise dos artigos, em relação ao questionamento 5, emergiram os seguintes grupos: 1) Pré-teste e pós-teste; 2) Resolução de problemas; 3) Construção de mapas conceituais; 4) Navegação em sistema hipermídia; 5) Elaboração e defesa de um projeto; 6)

11 São eles: caso, mini caso, tema de análise conceitual, comentário temático e travessia temática (SPIRO; JEHNG, 1990; PEDRO, 2005). 
Diário de observação; 7) Questionário sobre conceitos; 8) Questionário de opinião; 9) Entrevista; 10) Não implementada e avaliada.

A tabela 6 ilustra a quantidade de artigos encontrada para cada grupo, bem como os autores destes artigos.

Tabela 6 - Agrupamento dos artigos quanto ao instrumento de avaliação ${ }^{12}$.

\begin{tabular}{|l|c|l|}
\hline \multicolumn{1}{|c|}{ Grupo } & $\begin{array}{l}\text { Qtde de } \\
\text { artigos }\end{array}$ & \multicolumn{1}{|c|}{ Autores } \\
\hline 1. Pré-teste e pós-teste & 5 & $\begin{array}{l}\text { REZENDE (2001), GIRWIDZ et al. (2006), REZENDE, } \\
\text { GARCIA e COLA (2006), LIU e HMELO-SILVER (2009), } \\
\text { REZENDE, SOUSA e BARROS (2012) }\end{array}$ \\
\hline 2. Resolução de problemas & 2 & $\begin{array}{l}\text { REZENDE, GARCIA e COLA (2006), LIU e HMELO- } \\
\text { SILVER (2009) }\end{array}$ \\
\hline $\begin{array}{l}\text { 3. Construção de mapas } \\
\text { conceituais }\end{array}$ & 2 & $\begin{array}{l}\text { BOLACHA e AMADOR (2003), REZENDE, GARCIA e } \\
\text { COLA (2006) }\end{array}$ \\
\hline $\begin{array}{l}\text { 4. Navegação em sistema } \\
\text { hipermídia }\end{array}$ & 3 & $\begin{array}{l}\text { REZENDE (2001), REZENDE, GARCIA e COLA (2006), } \\
\text { REZENDE, SOUSA e BARROS (2012) }\end{array}$ \\
\hline $\begin{array}{l}\text { 5. Elaboração e defesa de um } \\
\text { projeto }\end{array}$ & 1 & VASCONCELOS e LEÃO (2012) \\
\hline 6. Diário de observação & 1 & BOLACHA e AMADOR (2003) \\
\hline $\begin{array}{l}\text { 10. Não implementada e } \\
\text { avaliada }\end{array}$ & 3 & $\begin{array}{l}\text { BOLACHA e AMADOR (2003), ABEGG et al. (2012), } \\
\text { VASCONCELOS e LEÃO (2012) }\end{array}$ \\
\hline $\begin{array}{l}\text { 8. Questionário de opinião } \\
\text { 9. Entrevista }\end{array}$ & $\begin{array}{l}\text { REZENDE, GARCIA e COLA (2006), ABEGG et al. } \\
\text { (2012), REZENDE, SOUSA e BARROS (2012) }\end{array}$ \\
\hline REZre conceitos & RIDMAR, DE BASTOS e ABEGG (2014), JOSÉ e DE \\
BASTOS (2017)
\end{tabular}

12 É possível notar que a soma dos artigos excede o total de doze. Isto ocorre pelo fato de que identificamos mais de um instrumento de avaliação no artigo de Rezende (2001), Bolacha e Amador (2003), Rezende, Garcia e Cola (2006), Liu e Hmelo-Silver (2009), Abegg et al. (2012), Rezende, Sousa e Barros (2012), Vasconcelos e Leão (2012). 
Analisando a tabela 6, identificamos que a maior parte das propostas utilizou préteste e pós-teste como instrumento de avaliação. Já a menor parte delas teve como instrumento o diário de observação ou a elaboração e defesa de um projeto.

É importante enfatizar a variedade de instrumentos de avaliação, que geram uma grande quantidade e diversidade de dados do ponto de vista da análise dos aspectos necessários para o desenvolvimento da flexibilidade cognitiva. Por meio da resolução de problemas, por exemplo, os estudantes podem aplicar os conhecimentos científicos em situações distintas daquelas originalmente trabalhadas.

Já através da construção de mapas conceituais, é possível perceber as ligações que os estudantes estabelecem entre os conceitos abordados, como destacam Bolacha e Amador (2003), que analisaram os mapas a partir dos níveis de hierarquização. No âmbito da TFC, um mesmo mini caso pode ser analisado a partir de diferentes temas de análise conceitual interligados, de modo que essa ligação entre os conceitos é essencial para o entendimento dos mini casos e casos, e, com isso, para o processo de reconstrução conceitual (ALEIXO, 2008).

Ainda, a análise da navegação em um sistema hipermídia, como aquela realizada por Rezende, Sousa e Barros (2012), possibilita acompanhar o caminho utilizado pelos estudantes; ou seja, como eles transitaram pelos casos, mini casos e temas de análise conceitual (SPIRO; JEHNG, 1990). Entendemos que isso pode contribuir para avaliar as travessias temáticas realizadas, fornecendo indícios para avaliação de alguns aspectos necessários para o desenvolvimento da flexibilidade cognitiva.

\section{IV.3.2.6 Foco de avaliação}

Da análise dos artigos, em relação ao questionamento 6 , identificamos diversos focos de avaliação para a análise dos dados obtidos a partir dos referidos instrumentos. São eles: 1) Compreensão dos conceitos; 2) Ligação entre $\operatorname{conceitos}^{13}$; 3) Ligação entre conceitos e situações concretas ${ }^{14}$; 4) Aplicação do conhecimento15; 5) Conhecimento prévio; 6) Reestruturação e desenvolvimento conceitual; 7) Visualização dos fenômenos; 8) Padrão de navegação em sistema hipermídia' ${ }^{16}$; 9) Atitude em relação ao componente curricular ${ }^{17}$; 10) Não implementada e avaliada.

\footnotetext{
13 Estabelecimento de relações entre conceitos distintos, porém interligados na estrutura conceitual de uma determinada área do conhecimento. Por exemplo, potência e corrente elétrica.

14 Explicitação de como um conceito científico pode ser utilizado para a análise de uma situação concreta. Por exemplo, de que forma os conceitos de potência e corrente elétrica nos ajudam a entender o que acontece com a resistência elétrica de um chuveiro quando alteramos a posição da haste, no sentido de aumentar a temperatura da água para o banho.

15 Utilização de um conceito científico em contexto(s) distinto(s) daquele no qual esse conceito foi inicialmente abordado.

16 Análise dos caminhos percorridos pelo sujeito ao longo de sua interatividade com um sistema hipermídia (REZENDE; SOUSA; BARROS, 2012).
} 
A tabela 7 ilustra a quantidade de artigos encontrada para cada grupo, bem como os autores destes artigos.

Tabela 7 - Agrupamento dos artigos quanto ao foco de avaliação ${ }^{18}$.

\begin{tabular}{|c|c|c|}
\hline Grupo & $\begin{array}{l}\text { Qtde de } \\
\text { artigos }\end{array}$ & Autores \\
\hline 1. Compreensão dos conceitos & 5 & $\begin{array}{l}\text { BOLACHA e AMADOR (2003), GIRWIDZ et al. (2006), } \\
\text { LIU e HMELO-SILVER (2009), ABEGG et al. (2012), } \\
\text { VASCONCELOS e LEÃO (2012) }\end{array}$ \\
\hline 2. Ligação entre conceitos & 3 & $\begin{array}{l}\text { BOLACHA e AMADOR (2003), REZENDE, GARCIA e } \\
\text { COLA (2006), LIU e HMELO-SILVER (2009) }\end{array}$ \\
\hline $\begin{array}{l}\text { 3. Ligação entre conceitos e } \\
\text { situações concretas }\end{array}$ & 2 & $\begin{array}{l}\text { REZENDE, GARCIA e COLA (2006), VASCONCELOS e } \\
\text { LEÃO (2012) }\end{array}$ \\
\hline 4. Aplicação do conhecimento & 1 & GIRWIDZ et al. (2006) \\
\hline 5. Conhecimento prévio & 3 & $\begin{array}{l}\text { REZENDE (2001), REZENDE, SOUSA e BARROS (2012), } \\
\text { VASCONCELOS e LEÃO (2012) }\end{array}$ \\
\hline $\begin{array}{l}\text { 6. Reestruturação e } \\
\text { desenvolvimento conceitual }\end{array}$ & 1 & REZENDE (2001) \\
\hline 7. Visualização dos fenômenos & 1 & ABEGG et al. (2012) \\
\hline $\begin{array}{l}\text { 8. Padrão de navegação em } \\
\text { sistema hipermídia }\end{array}$ & 1 & REZENDE, SOUSA e BARROS (2012) \\
\hline $\begin{array}{l}\text { 9. Atitude em relação ao } \\
\text { componente curricular }\end{array}$ & 1 & REZENDE, GARCIA e COLA (2006) \\
\hline $\begin{array}{l}\text { 10. Não implementada e } \\
\text { avaliada }\end{array}$ & 4 & $\begin{array}{l}\text { REZENDE e COLA (2004), LEÃO e NERI (2009), } \\
\text { VIDMAR, DE BASTOS e ABEGG (2014), JOSÉ e de } \\
\text { BASTOS (2017) }\end{array}$ \\
\hline
\end{tabular}

\footnotetext{
17 Avaliação da atitude dos estudantes a partir de uma escala de atitudes em relação a um componente curricular específico, composta pelas subescalas conteúdo, professor, aplicabilidade e sensações (REZENDE; GARCIA; COLA, 2006).

${ }^{18}$ É possível notar que a soma dos artigos excede o total de doze. Isto ocorre pelo fato de que identificamos mais de um foco de avaliação no artigo de Rezende (2001), Bolacha e Amador (2003), Girwidz et al. (2006), Rezende, Garcia e Cola (2006), Liu e Hmelo-Silver (2009), Abegg et al. (2012), Rezende, Sousa e Barros (2012), Vasconcelos e Leão (2012).
} 
Analisando a tabela 7, identificamos que a maior parte das propostas teve como foco de avaliação a compreensão dos conceitos. No caso do trabalho de Vasconcelos e Leão (2012), por exemplo, essa compreensão foi voltada aos conceitos envolvidos nos benefícios e malefícios da radioatividade. Destacamos que essa avaliação é fundamental, uma vez que, em se tratando de conhecimentos de nível avançado, a compreensão dos conceitos é essencial para que seja possível aplicá-los de maneira flexível em um novo contexto (SPIRO et al., 1988; SPIRO et al., 1992; CARVALHO, 1998, 2000, 2011; SPIRO; COLLINS; RAMCHANDRAN, 2007b).

Em relação aos focos de avaliação menos presentes nas propostas, enfatizamos a aplicação do conhecimento, entendida como a transferência dos conhecimentos científicos em situações novas (SPIRO; JEHNG, 1990). Esse aspecto também foi pouco explorado nas metodologias de ensino, sendo que, conforme discutimos naquela ocasião, ele está diretamente associado ao conceito de flexibilidade cognitiva.

Assim como ocorreu com os instrumentos de avaliação, é importante enfatizar a diversidade de focos de avaliação, que possibilita uma análise abrangente dos aspectos envolvidos no desenvolvimento da flexibilidade cognitiva. Quando analisamos a aplicação do conhecimento por parte dos estudantes, por exemplo, temos indícios a respeito do desenvolvimento da flexibilidade cognitiva (SPIRO; JEHNG, 1990).

Já quando realizamos uma avaliação com foco nas ligações estabelecidas pelos estudantes entre conceitos e situações concretas, é possível perceber em que medida foram operacionalizados os comentários temáticos e travessias temáticas (SPIRO; JEHNG, 1990; CARVALHO et al., 2002; REZENDE; COLA, 2004; SOUSA, 2004; PEDRO, 2005; PINHO, 2006; MOREIRA; PEDRO; NOGUEIRA, 2011). Isso foi consubstanciado no trabalho de Rezende, Garcia e Cola (2006), que abordaram aplicações biomecânicas e anatômicas de conceitos de mecânica.

\section{Considerações finais}

Como um dos resultados dessa revisão bibliográfica, constatamos que a flexibilidade cognitiva ainda é pouco trabalhada no âmbito do ensino de Ciências, tendo em vista a pequena quantidade de artigos encontrada (dezoito) em um número considerável de periódicos e intervalo de tempo (trinta e três periódicos em vinte e sete anos). Isso explicita a relevância e necessidade de ampliação das investigações sobre a temática, inclusive no que diz respeito a uma revisão bibliográfica em dissertações e teses, a qual não abrangeu o escopo de nosso trabalho.

Em relação ao primeiro objetivo principal da pesquisa bibliográfica - situar a flexibilidade cognitiva nas áreas de ensino e pesquisa em ensino de Ciências -, sistematizamos os trabalhos com ênfase na flexibilidade cognitiva em três categorias, relacionadas à natureza dos mesmos: desenvolvimento, implementação e/ou avaliação de 
sistema hipermídia; elaboração, implementação e/ou avaliação de atividade; e abordagem de aspectos teóricos.

Nesse contexto, constatamos que a menor parte dos trabalhos está relacionada à elaboração, implementação e/ou avaliação de atividade, o qual justamente buscamos subsídios para consubstanciar o desenvolvimento da flexibilidade cognitiva. Outro resultado importante consistiu na inexistência de artigos de revisão de literatura sobre flexibilidade cognitiva no ensino de Ciências, de modo que nossa revisão bibliográfica se mostrou pertinente nesse âmbito.

Já em relação ao segundo objetivo principal - buscar subsídios para a elaboração e avaliação de atividades didáticas de Física -, sistematizamos os trabalhos com ênfase na flexibilidade cognitiva que continham propostas de recurso didático ou atividade, quanto ao: nível de ensino, temática, recurso didático, metodologia de ensino, instrumento de avaliação e foco de avaliação.

Destacamos como um dos resultados obtidos a diversidade de metodologias de ensino presente nas propostas analisadas. Entendemos que essa diversidade pode contribuir para a elaboração de atividades didáticas de Física em consonância com a estrutura principal da TFC, tendo em vista abordar os aspectos necessários para o desenvolvimento da flexibilidade cognitiva, discutidos ao longo do texto.

Em termos de avaliação, a diversidade de instrumentos e focos de avaliação encontrada nas propostas gera uma ampla gama de dados. Entendemos que isso possibilita a definição de critérios de análise coerentes com os aspectos necessários para o desenvolvimento da flexibilidade cognitiva.

Nesse sentido, explicitamos como principais implicações desta pesquisa a discussão da importância da flexibilidade cognitiva para o ensino de Ciências, em geral, e da Física, em particular. A partir dos resultados obtidos na etapa em que situamos a flexibilidade cognitiva na área de ensino e pesquisa em ensino de Ciências, reforçamos a necessidade de ampliação das investigações sobre a temática, tanto em relação a discussões teóricas quanto à elaboração, implementação e avaliação de práticas concretas associadas à flexibilidade cognitiva. Sobre esta última, sublinhamos a contribuição desta pesquisa no sentido de fornecer subsídios - em termos de recursos didáticos, metodologias de ensino e instrumentos e focos de avaliação - para consubstanciar o desenvolvimento da flexibilidade cognitiva nesse contexto.

Para finalizar, enfatizamos que a TFC está voltada especificamente para a construção de conhecimentos de nível avançado (SPIRO et al., 1988; SPIRO; JEHNG, 1990; CARVALHO, 1998, 2000; PINHO, 2006), em que é necessária uma compreensão profunda dos conhecimentos complexos (SPIRO et al., 1988; SPIRO et al., 1992; CARVALHO, 1998, 2000, 2011; SPIRO; COLLINS; RAMCHANDRAN, 2007b; SILVA; DOTTA, 2018). 
Além disso, a referida teoria visa à aplicação desses conhecimentos de maneira flexível em um novo contexto. Nessa linha, Heidrich (2009) destaca que a característica de complexidade está presente nas situações que envolvem aplicação prática de conhecimentos.

Nesse âmbito de complexidade de aprendizagem, consideramos que uma diversidade de metodologias de ensino, instrumentos de avaliação e focos de avaliação pode nos proporcionar um processo de ensino-aprendizagem de Física mais flexível, além de uma análise coerente e abrangente dos aspectos envolvidos no desenvolvimento da flexibilidade cognitiva. Flexibilidade essa que, conforme procuramos argumentar, é essencial para uma formação mais ampla e articulada, que visa à aplicação do conhecimento em novos contextos.

\section{Referências bibliográficas}

ALEIXO, A. A. FlexQuest no Ensino de Ciências: Incorporando a Teoria da Flexibilidade Cognitiva na WebQuest. 2008. 157 f. Dissertação (Mestrado em Ensino das Ciências) Universidade Federal Rural de Pernambuco, Recife.

ARANTES, A. R.; MIRANDA, M. S.; STUDART, N. Objetos de aprendizagem no ensino de física: usando simulações do PhET. Física na Escola, São Paulo, v. 11, n. 1, p. 27-31, 2010.

BRASIL. Ministério da Educação. PCN+ Ensino Médio: orientações educacionais complementares aos Parâmetros Curriculares Nacionais. Ciências da Natureza, Matemática e suas Tecnologias. Brasília, 2002.

BRASIL. Ministério da Educação. Orientações Curriculares para o Ensino Médio. Ciências da Natureza, Matemática e suas Tecnologias. Brasília, 2006.

BRASIL. Ministério da Educação. Diretrizes Curriculares Nacionais da Educação Básica. Brasília, 2013.

CARVALHO, A. A. A. Os documentos hipermédia estruturados segundo a teoria da flexibilidade cognitiva: importância dos comentários temáticos e das travessias temáticas na transferência do conhecimento para novas situações. 1998. Tese (Doutorado em Educação) Universidade do Minho, Braga.

CARVAlHO, A. A. A. A representação do conhecimento segundo a Teoria da Flexibilidade Cognitiva. Revista Portuguesa de Educação, v. 13, n. 1, p. 169-184, 2000.

CARVAlHO, A. A. A.; PINTO, C. S.; BAPTISTA, A. A.; MONTEIRO, P. J. M. Desenvolvimento de flexibilidade cognitiva através da plataforma web FleXml. In: 
CONFERENCIA IBERO-AMERICANA EN SISTEMAS, CIBERNÉTICA E INFORMÁTICA, 1, 2002, Orlando. Anais eletrônicos... Orlando: CISCI, 2002.

CARVALHO, A. A. A.; PINTO, C. S.; MONTEIRO, P. J. M. FleXml: Plataforma de Ensino a Distância para Promover Flexibilidade Cognitiva. In: SIMPÓSIO INTERNACIONAL DE INFORMÁTICA EDUCATIVA, 4., 2002, Vigo. Anais eletrônicos... Vigo: RIBIE, 2002. Disponível em: <http://www.niee.ufrgs.br/eventos/RIBIE/2002/actas/paper-075.pdf>. Acesso em: 10 ago. 2020.

CARVAlHO, A. A. A. A Teoria da Flexibilidade Cognitiva e o Modelo Múltiplas Perspectivas. In: LEÃO, M. B. C. (Org.) Tecnologias na Educação: uma abordagem crítica para uma atuação prática. Recife: UFRPE, 2011. p. 17-42.

DESCHRYVER, M.; SPIRO, R. J. New Forms of Deep Learning on the Web: Meeting the Challenge of Cognitive Load in Conditions of Unfettered Exploration in Online Multimedia Environments. In: ZHENG, R. Z. (Ed.). Cognitive Effects of Multimedia Learning. Hershey: IGI Global, 2009, p. 134-152.

DIAS, P. Hipertexto, hipermédia e media do conhecimento: representação distribuída e aprendizagens flexíveis e colaborativas na Web. Revista Portuguesa de Educação, v. 13, n. 1, p. 141-167, 2000.

ECHEVERRÍA, M. P. P.; POZO, J. I. Aprender a resolver problemas e resolver problemas para aprender. In: POZO, J. I. (Org.). A solução de Problemas. Porto Alegre: Artmed, 1998, p. 13-42.

GIL, A. C. Como Elaborar Projetos de Pesquisa. 4. ed. São Paulo: Atlas, 2002.

GUERRA, C. G. Flexibilidade Cognitiva e Rendimento Escolar: estudo com alunos do Instituto Politécnico de Portalegre. In: SEMINÁRIO de I\&DT, 3, 2012, Portalegre. Anais eletrônicos... Portalegre: Instituto Politécnico de Portalegre, 2012. Disponível em: $<$ http://www.c3i.ipportalegre.pt/uploads/COMUNICACOES_III\%20Seminario\%20IDT.pdf $>$. Acesso em: 10 ago. 2020.

HEIDRICH, D. N. Construção e avaliação de hipermídia educacional sobre tópicos de carboidratos. 2009. 269 f. Tese (Doutorado em Educação Científica e Tecnológica) Universidade Federal de Santa Catarina, Santa Catarina. 
LEÃO, M. B. C.; SOUZA, F. N.; MOREIRA, A. FlexQuest: literacia da informação e flexibilidade cognitiva. Indagatio Didactica, v. 3, n. 3, p. 108-125, 2011.

LEITE, B. S. Uso das tecnologias para o Ensino das Ciências: a Web 2.0 como ferramenta de aprendizagem. 2011. 286 f. Dissertação (Mestrado em Ensino das Ciências) Universidade Federal Rural de Pernambuco, Recife.

LEITE, B. S.; LEÃO, M. B. C. Contribuição da Web 2.0 como ferramenta de aprendizagem: um estudo de caso. Revista Brasileira de Ensino de Ciência e Tecnologia, Ponta Grossa, v. 8, n. 4, p. 288-315, 2015.

MARQUES, C. G. C.; CARVALHO, A. A. A.; GUIMARÃES, N. Integração dos princípios da Teoria da Flexibilidade Cognitiva no hiperdocumento "Arquitectura de Computadores": testes de usabilidade realizados. Revista Portuguesa de Educação, v. 17, n. 1, p. 151-189, 2004.

MOREIRA, A.; PEDRO, L.; NOGUEIRA, F. DidaktosOnLine: um ambiente virtual de aprendizagem baseado na Teoria da Flexibilidade Cognitiva. In: LEÃO, M. B. C. (Org.) Tecnologias na Educação: uma abordagem crítica para uma atuação prática. Recife: UFRPE, 2011. p. 133-147.

OLIVEIRA, J. A. B.; SILVA, C. J.; AQUINO, K. A. S. Aprendizagem Significativa Crítica e Flexibilidade Cognitiva: diálogo metodológico através da construção e validação de uma ferramenta Flexquest para o ensino de Ecologia na educação básica. Revista Cadernos de Estudos e Pesquisa na Educação Básica, v. 3, n. 1, p. 35-51, 2017.

PEDRO, L. F.; MOREIRA, A. Os Hipertextos de Flexibilidade Cognitiva e a planificação de conteúdos didácticos: um estudo com (futuros) professores de Línguas. Revista de Enseñanza y Tecnología, p. 29-35, sept./dic. 2000.

PEDRO, L. F. A construção de materiais didácticos por recurso a um hipertexto de flexibilidade cognitiva: um estudo comparativo. 2005. $643 \mathrm{f}$. Tese (Doutorado em Didáctica) - Universidade de Aveiro, Aveiro.

PESSOA, T.; NOGUEIRA, F. Flexibilidade Cognitiva nas vivências e práticas educativas. In: NASCIMENTO, A., HETKOWSKI, T. (Org.). Educação e contemporaneidade: pesquisas científicas e tecnológicas. Salvador: EDUFBA, 2009. p. 109-131. 
PINHO, S. P. S. R. Padrões de Interacção num Ambiente de Aprendizagem Colaborativa a Distância: Um estudo de caso com conteúdos estruturados segundo a Teoria da Flexibilidade Cognitiva. 2006. 252 f. Dissertação (Mestrado em Multimédia em Educação) Universidade de Aveiro, Aveiro.

POZO, J. I.; CRESPO, M. A. G. A aprendizagem e o ensino de ciências: do conhecimento cotidiano ao conhecimento científico. Porto Alegre: Artmed, 2009. 296 p.

RAMOS, D. K.; SEGUNDO, F. R. S. Jogos Digitais na Escola: aprimorando a atenção e a flexibilidade cognitiva. Educação \& Realidade, v. 43, n. 2, p. 531-550, abr.jun. 2018.

REZENDE, F. Desenvolvimento e avaliação de um sistema hipermídia para facilitar a reestruturação conceitual em Mecânica Básica. Caderno Brasileiro de Ensino de Física, Florianópolis, v. 18, n. 2, p. 197-213, 2001.

REZENDE, F.; COLA, C. dos S. D. Hipermídia na educação: flexibilidade cognitiva, interdisciplinaridade e complexidade. Ensaio Pesquisa em Educação em Ciências, Belo Horizonte, v. 6, n. 2, p. 1-11, 2004.

REZENDE, F.; GARCIA, M. A. C.; COLA, C. dos S. D. Desenvolvimento e avaliação de um sistema hipermídia que integra conceitos básicos de Mecânica, Biomecânica e Anatomia Humana. Investigações em Ensino de Ciências, Porto Alegre, v. 11, n. 2, p. 239-259, 2006.

SILVA, E. R.; DOTTA, S. Interfaces da flexibilidade cognitiva e da aprendizagem em fóruns de discussão. Revista Iberoamericana de Educación a Distancia, v. 21, n. 1, p. 303-322, 2018 .

SILVA, I. G. S. S.; LEÃO, M. B. C.; SOUZA, F. N. Plataforma FlexQuest: Uma estratégia didática para a promoção de flexibilidade cognitiva e interdisciplinaridade com recursos Web 2.0. Revista lbérica de Sistemas e Tecnologias de Informação, n. E4, p. 35-49, 2015.

SOUSA, A. A. A. Aplicação da Teoria da Flexibilidade Cognitiva ao $1^{\circ}$ Ciclo do Ensino Básico: Um Estudo Sobre a Qualidade do Ambiente. 2004. 172 f. Dissertação (Mestrado em Educação) - Universidade do Minho, Braga.

SOUZA, R. V.; LEÃO, M. B. C. O processo de construção da FlexQuest por professores de ciências: análise de alguns saberes necessários. Ciência \& Educação, Bauru, v. 21, n. 4, p. 1049-1062, 2015. 
SPIRO, R. J.; COUlSON, R. L.; FELTOVICH, P. J.; ANDERSON, D. K. Cognitive Flexibility Theory: Advanced Knowledge Acquisition in Ill-Structured Domains. In: PATEL, V. L.; GROEN, G. J. (Eds.). Proceedings of the 10th Annual Conference of the Cognitive Science Society. Hillsdale: Lawrence Erlbaum Associates, 1988. p. 375-383.

SPIRO, R. J.; JEHNG, J. C. Cognitive Flexibility and Hypertext: Theory and Technology for the Nonlinear and Multidimensional Traversal of Complex Subject Matter. In: NIX, D.; SPIRO, R. J. (Eds.). Cognition, Education, and Multimedia: Exploring Ideas in High Technology. Hillsdale: Lawrence Erlbaum Associates, 1990. p. 163-205.

SPIRO, R. J.; FELTOVICH, P. J.; JACOBSON, M. J.; COULSON, R. L. Cognitive Flexibility, Constructivism, and Hypertext: Random Acess Instruction for Advanced Knowledge Acquisition in Ill-Structured Domains. In: DUFFY, T. M.; JONASSEN, D. H. (Eds.). Constructivism and the Technology of Instruction: A Conversation. Hillsdale: Lawrence Erlbaum Associates, 1992. p. 57-75.

SPIRO, R. J.; COLLINS, B. P.; RAMCHANDRAN, A. R. Modes of Openness and Flexibility in Cognitive Flexibility Hypertext Learning Environments. In: KHAN, B. (Ed.). Flexible learning in an information society. Hershey: Information Science Publishing, 2007a. p. 1825 .

SPIRO, R. J.; COLLINS, B. P.; RAMCHANDRAN, A. R. Reflections on a Post-Gutenberg Epistemology for Video Use in Ill-Structured Domains: Fostering Complex Learning and Cognitive Flexibility. In: GOLDMAN, R.; PEA, R.; BARRON, B.; DERRY, S. J. (Eds.). Video research in the Learning Sciences. Mahwah: Lawrence Erlbaum Associates, 2007b. p. 93-100.

VASCONCELOS, F. C. G. C.; LEÃO, M. B. C. Utilização de recursos audiovisuais em uma estratégia FlexQuest sobre Radioatividade. Investigações em Ensino de Ciências, Porto Alegre, v. 17, n. 1, p. 37-58, 2012.

\section{Artigos analisados}

ABEGG, I.; DE BASTOS, F. da P.; VIDMAR, M. P.; RICHTER, S. S. Ensino de Física: Investigando os Benefícios da Mediação Tecnológica Educacional. Revista Dynamis, Blumenau, v. 18, n. 1, p. 21-34, 2012.

BOLACHA, E.; AMADOR, F. Organização do conhecimento, construção de hiperdocumentos e ensino das Ciências da Terra. Investigações em Ensino de Ciências, Porto Alegre, v. 8, n. 1, p. 31-52, 2003. 
CHIN, C.; CHIA, L. Problem-Based Learning: Using Ill-Structured Problems in Biology Project Work. Science Education, v. 90, n. 1, p. 44-67, 2006.

EILAM, B.; REITER, S. Long-Term Self-Regulation of Biology Learning Using Standard Junior High School Science Curriculum. Science Education, v. 98, n. 4, p. 705-737, 2014.

ESTEVES, Y. G.; GUIILLÉN, C. D. Propuesta de arquitectura para un software educativo en el dominio de la enseñanza de la física que concilie el modelo del negocio con las mejores prácticas de las ciencias de la computación. Enseñanza de las Ciencias, n. Extra, p. 2765$2772,2009$.

FERNANDES, L. S.; CAMPOS, A. F. Pesquisas em periódicos nacionais e internacionais sobre o ensino e aprendizagem de ligação química. Revista Brasileira de Pesquisa em Educação em Ciências, Belo Horizonte, v. 12, n. 2, p. 153-172, 2012.

FOLMER, V.; BARBOSA, N. B. V.; SOARES, F. A.; ROCHA, J. B. T. Experimental activities based on ill-structured problems improve Brazilian school students' understanding of the nature of scientific knowledge. Revista Electrónica de Enseñanza de las Ciencias, v. 8 , n. 1, p. 232-254, 2009.

FRAIHA-MARTINS, F.; GONÇALVES, T. V. O. Informática na educação matemática e científica dos anos iniciais de escolaridade: um estudo sobre as pesquisas da área Ensino de Ciências e Matemática. Ensaio Pesquisa em Educação em Ciências, Belo Horizonte, v. 14, n. 3, p. 313-331, 2012.

GIRWIDZ, R.; BOGNER, F. X.; RUBITZKO, T.; SCHAAL, S. Media-assisted Learning in Science Education: An Interdisciplinary Approach to Hibernation and Energy Transfer. Science Education International, v. 17, n. 2, p. 95-107, 2006.

HOYOS, E.; POCOVÍ, M. C. Aprendizaje avanzado: comprensión del concepto de "invariancia" a partir de textos. Revista de Enseñanza de la Física, v. 29, n. Extra, p. 75-86, 2017.

JOSÉ, W. D.; DE BASTOS, F. da P. Trabalho colaborativo no ensino de Física mediado por tecnologias educacionais em rede para resolução de problemas. Revista Electrónica de Enseñanza de las Ciencias, v. 16, n. 1, p. 47-68, 2017.

LEÃO, M. B. C.; NERI, F. FlexQuest: una webquest con aportes de la Teoria de la Flexibilidad Cognitiva (TFC). Enseñanza de las Ciencias, n. Extra, p. 569-573, 2009. 
LEITE, B. S.; LEÃO, M. B. C. Contribuição da Web 2.0 como ferramenta de aprendizagem: um estudo de caso. Revista Brasileira de Ensino de Ciência e Tecnologia, Ponta Grossa, v. 8, n. 4, p. 288-315, 2015.

LIU, L.; HMELO-SILVER, C. E. Promoting Complex Systems Learning through the Use of Conceptual Representations in Hypermedia. Journal of Research in Science Teaching, v. 46, n. 9, p. 1023-1040, 2009.

MOZENA. E. R.; OSTERMANN, F. Uma revisão bibliográfica sobre a interdisciplinaridade no Ensino das Ciências da Natureza. Ensaio Pesquisa em Educação em Ciências, Belo Horizonte, v. 16, n. 2, p. 185-206, 2014.

REZENDE, F. Desenvolvimento e avaliação de um sistema hipermídia para facilitar a reestruturação conceitual em Mecânica Básica. Caderno Brasileiro de Ensino de Física, Florianópolis, v. 18, n. 2, p. 197-213, 2001.

REZENDE, F. As novas tecnologias na prática pedagógica sob a perspectiva construtivista. Ensaio Pesquisa em Educação em Ciências, Belo Horizonte, v. 2, n. 1, p. 75-98, 2002.

REZENDE, F.; COLA, C. dos S. D. Hipermídia na educação: flexibilidade cognitiva, interdisciplinaridade e complexidade. Ensaio Pesquisa em Educação em Ciências, Belo Horizonte, v. 6, n. 2, p. 1-11, 2004.

REZENDE, F.; GARCIA, M. A. C.; COLA, C. dos S. D. Desenvolvimento e avaliação de um sistema hipermídia que integra conceitos básicos de Mecânica, Biomecânica e Anatomia Humana. Investigações em Ensino de Ciências, Porto Alegre, v. 11, n. 2, p. 239-259, 2006.

REZENDE, F.; SOUSA, J. J. F.; BARROS, S. S. Padrões de navegação em um sistema hipermídia de Mecânica Básica. Caderno Brasileiro de Ensino de Física, Florianópolis, v. 29, n. Especial 1, p. 361-389, 2012.

SAVELSBERGH, E. R.; DE JONG, T.; FERGUSON-HESSLER, M. G. M. Situational Knowledge in Physics: The Case of Electrodynamics. Journal of Research in Science Teaching, v. 39, n. 10, p. 928-951, 2002.

SOUZA, R. V.; LEÃO, M. B. C. O processo de construção da FlexQuest por professores de ciências: análise de alguns saberes necessários. Ciência \& Educação, Bauru, v. 21, n. 4, p. 1049-1062, 2015. 
VASCONCELOS, F. C. G. C.; LEÃO, M. B. C. Utilização de recursos audiovisuais em uma estratégia FlexQuest sobre Radioatividade. Investigações em Ensino de Ciências, Porto Alegre, v. 17, n. 1, p. 37-58, 2012.

VIDMAR, M. P.; DE BASTOS, F. da P.; ABEGG, I. Flexibilidade cognitiva e hipermídia educacional na formação inicial de físicos-educadores. Revista Brasileira de Pesquisa em Educação em Ciências, Belo Horizonte, v. 14, n. 3, p. 101-118, 2014.

VIDMAR, M. P.; DE BASTOS, F. da P.; ABEGG, I.; SAUERWEIN, I. P. S. Contribuições da hipermídia educacional para o desenvolvimento de Atividades de Estudo de Física. Revista de Enseñanza de la Física, v. 27, n. Extra, p. 69-77, 2015.

VOSNIADOU, S.; LOANNIDES, C. From conceptual development to science education: a psychological point of view. International Journal of Science Education, v. 20, n. 10, p. 1213-1230, 1998. 